\title{
Numerical Calculation of the Horizontal Stress Difference of Viscous-Elastic Fluid Acting on the Residual Oil in Micro Pore
}

\author{
Lili Liu1, Shuren Yang1, Lihui Wang2, Di Xu1, Liang Zhao³, Yue Cui1 \\ ${ }^{1}$ Petroleum Engineering Department, Northeast Petroleum University, Daqing, China \\ ${ }^{2}$ Daqing Petroleum Equipment Group, Daqing, China \\ ${ }^{3}$ Daqing Oilfield Tianyu Engineering Design Co., Ltd., Daqing, China \\ Email: dqliull2009@163.com
}

Received 13 March 2014; revised 13 April 2014; accepted 20 April 2014

Copyright (C) 2014 by authors and Scientific Research Publishing Inc. This work is licensed under the Creative Commons Attribution International License (CC BY). http://creativecommons.org/licenses/by/4.0/

\section{(c) (i) Open Access}

\begin{abstract}
In order to analyze the microscopic theory of viscous-elastic fluid flooding residual oil, the flow equation of polymer solution in the micro pore can be derived by selecting upper-convected Maxwell constitutive equation, continuity equation and motion equation. Then, the flow velocity field and stress field can be calculated under the boundary condition, and with the theory of stress tensor, the horizontal stress difference of polymer solution acting on the residual oil can be calculated. The results show that the greater the elasticity of viscous-elastic fluid is, the wider the flow channel is, the greater the horizontal stress difference is. The force acting on residual oil by viscous-elastic fluid can be increased by increasing the concentration of the polymer solution.
\end{abstract}

\section{Keywords}

Viscous-Elastic Fluid, Upper-Convected Maxwell Constitutive Equation, Horizontal Stress Difference, We

\section{Introduction}

The practice of enhanced oil recovery shows that the recovery can be improved by the viscous-elastic polymer solution flooding. The conclusion that the greater the elasticity of viscous-elastic fluid is, the higher the sweep efficiency is, which has been derived through using the modified upper-convected Maxwell constitutive model by Yin Hongjun [1] [2] et al. The flow field of viscous-elastic fluid on the dead ends has been calculated and 
analyzed by Zhang Lijuan [3] et al. And conclusion that viscous-elastic fluid can improve oil displacement efficiency has been received by Wang Demin [4] [5], Xia Huifen [6] [7], et al. and they qualitative analyzed the microscopic force acting on residual oil in detail. And they pointed out that in the microscopic pore space, it is microscopic force that made the residual oil deform and separate.

In this paper, the microscopic force acting on the residual oil of viscous-elastic fluid has been calculated quantitative. And the microscopic force which made the residual oil deform is the horizontal stress difference acting on the residual oil at the same level, which lays the basis for the further analysis of deformation and separation of residual oil.

\section{The Mathematical Model of Upper-Convected Maxwell Viscous-Elastic Fluid in the Micro Pore}

\subsection{Flow Channel Model}

In order to analyze the force of the residual oil in micro pore of different flow channel width, the calculation model has been established in Figure 1. $H$ is width of the flow channel, taking $20 \mu \mathrm{m}, 40 \mu \mathrm{m}, 60 \mu \mathrm{m}$ respectively. The length of the flow channel is $80 \mu \mathrm{m}$. The oil film height is $10 \mu \mathrm{m}$.

\subsection{The Flow Equation of Upper-Convected Maxwell Viscous-Elastic Fluid}

The viscous-elastic fluid has complicated rheological characteristics. After the practical research, it is suitable for upper-convected Maxwell constitutive equation to describe the rheological characteristics of the viscouselastic fluid. And the continuity equation, motion equation and constitutive equation are as follows:

Continuity equation:

$$
\frac{\partial u}{\partial x}+\frac{\partial v}{\partial y}=0
$$

where: $u, v$ is the velocity in the $x, y$ direction respectively, $\mathrm{m} / \mathrm{s}$;

Motion equation:

$$
\begin{aligned}
& R \mathrm{e}\left(u \frac{\partial u}{\partial x}+v \frac{\partial u}{\partial y}\right)=-\frac{1}{\rho} \frac{\partial p}{\partial x}+\frac{\partial T^{x x}}{\partial x}+\frac{\partial T^{x y}}{\partial y} \\
& R \mathrm{e}\left(u \frac{\partial v}{\partial x}+v \frac{\partial v}{\partial y}\right)=-\frac{1}{\rho} \frac{\partial p}{\partial x}+\frac{\partial T^{x y}}{\partial x}+\frac{\partial T^{y y}}{\partial y}
\end{aligned}
$$

Upper-convected Maxwell constitutive equation [8]:

where: $\stackrel{\nabla}{\nabla i k}$ is the upper-convected derivative, the expression is

$$
\begin{gathered}
T^{i k}+\lambda T^{\nabla k}=\eta_{0} A^{i k} \\
\text { vected derivative, the expression is } \\
T^{\nabla k}=\frac{\partial T^{i k}}{\partial t}+v^{m} \frac{\partial T^{i k}}{\partial x^{m}}-T^{m k} \frac{\partial v^{i}}{\partial x^{m}}-T^{i m} \frac{\partial v^{k}}{\partial x^{m}}
\end{gathered}
$$

where: $A$ is the First Rivlin-Ericksen deformation tensor, the expression is

$$
A^{i k}=v^{i, j}+v^{j, i}
$$

Constitutive equation:

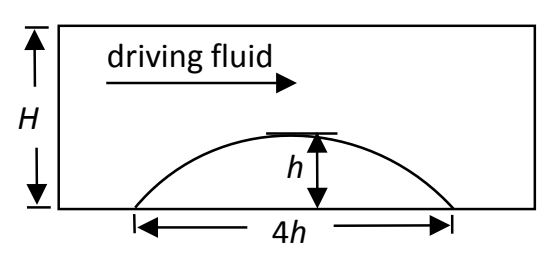

Figure 1. Calculation model. 


$$
\begin{gathered}
T^{x x}+W e\left(u \frac{\partial T^{x x}}{\partial x}+v \frac{\partial T^{x x}}{\partial y}-2 T^{x x} \frac{\partial u}{\partial x}-2 T^{x y} \frac{\partial u}{\partial y}\right)=2 \frac{\partial u}{\partial x} \\
T^{x y}+W e\left(u \frac{\partial T^{x y}}{\partial x}+v \frac{\partial T^{x y}}{\partial y}-T^{x y}\left(\frac{\partial u}{\partial x}+\frac{\partial v}{\partial y}\right)-T^{y y} \frac{\partial u}{\partial y}-T^{x x} \frac{\partial v}{\partial x}\right)=\frac{\partial u}{\partial y}+\frac{\partial v}{\partial x} \\
T^{y y}+W e\left(u \frac{\partial T^{y y}}{\partial x}+v \frac{\partial T^{y y}}{\partial y}-2 T^{x y} \frac{\partial v}{\partial x}-2 T^{y y} \frac{\partial v}{\partial y}\right)=2 \frac{\partial v}{\partial y}
\end{gathered}
$$

Make the motion equation and constitutive equation dimensionless and introduce the dimensionless parameters as follows: take $U$ (the average velocity of inlet) as the characteristic velocity; take $h$ (the width of inlet) as the characteristic length.

$$
\begin{aligned}
& x_{*}=\frac{x}{h}, \quad y_{*}=\frac{y}{h}, u_{*}=\frac{u}{U}, \quad v_{*}=\frac{v}{U}, T_{*}^{x x}=\frac{h T^{x x}}{\eta U}, T_{*}^{x y}=\frac{h T^{x y}}{\eta U} \\
& T_{*}^{y y}=\frac{h T^{y y}}{\eta U}, \quad p_{*}=\frac{h p}{\eta U}, \quad R e=\frac{\rho U h}{\eta}, W e=\lambda \frac{U}{h}
\end{aligned}
$$

For the sake of simplicity, “*” in the lower right corner is omitted.

\subsection{Boundary Condition}

1) The solid boundaries are all in the no-slip condition. And the boundary condition of wall is

$$
u=v=\frac{\partial u}{\partial y}=\frac{\partial u}{\partial x}=\frac{\partial v}{\partial x}=\frac{\partial v}{\partial y}=0
$$

2) The inlet and outlet are in the same pressure difference. The pressure gradient is $0.02 \mathrm{MPa} / \mathrm{m}$. And the boundary condition of the inlet is

$$
v=\frac{\partial u}{\partial x}=\frac{\partial v}{\partial x}=\frac{\partial v}{\partial y}=0, \frac{\partial T^{x x}}{\partial x}=\frac{\partial T^{x y}}{\partial x}=\frac{\partial T^{y y}}{\partial x}=0
$$

The boundary condition of outlet is: normal stress is 0 , tangential velocity is 0 .

\section{Calculation Result}

The oil micro pore of different permeability is calculated with the change of We, the variation curves of the horizontal stress difference are all shown in Figure 2.

From Figure 2, with the increase of We, the horizontal stress difference increases; And with the increase of the flow channel width, the horizontal stress difference increases, too. Because of the limitation of the calculation condition, the maximum value of We is 0.6 . In the practical reservoir, the We of polymer solution is greater than 0.6. In order to reflect the affection to horizontal stress difference of We in the real situation, the curves of the maximum of horizontal stress difference are shown in Figure 3.

Three conclusions can be got from Figure 3. First, the wider the flow channel (the higher the permeability) is, the greater the maximum of displacing force of residual oil is, vice versa. Second, the greater the We is, the greater the maximum curve slope of horizontal stress difference is. Namely, with the increasing of We, the increasing of horizontal stress difference maximum is faster. Third, in order to obtain the same force of horizontal displacement force, We is large when the flow channel is $20 \mu \mathrm{m}$. We is in the middle value when the flow channel is $40 \mu \mathrm{m}$. And it is lower when the flow channel is $60 \mu \mathrm{m}$. The third conclusion shows that it is easy to derive that the same displacing effect needs great $W e$ in low permeability reservoir. Although there are many ways to increasing $W e$, but in the limitation of field condition, the most effective way is increasing the polymer concentration.

\section{Conclusions}

1) The wider the flow channel is, the greater the permeability is. The horizontal stress difference acting on 


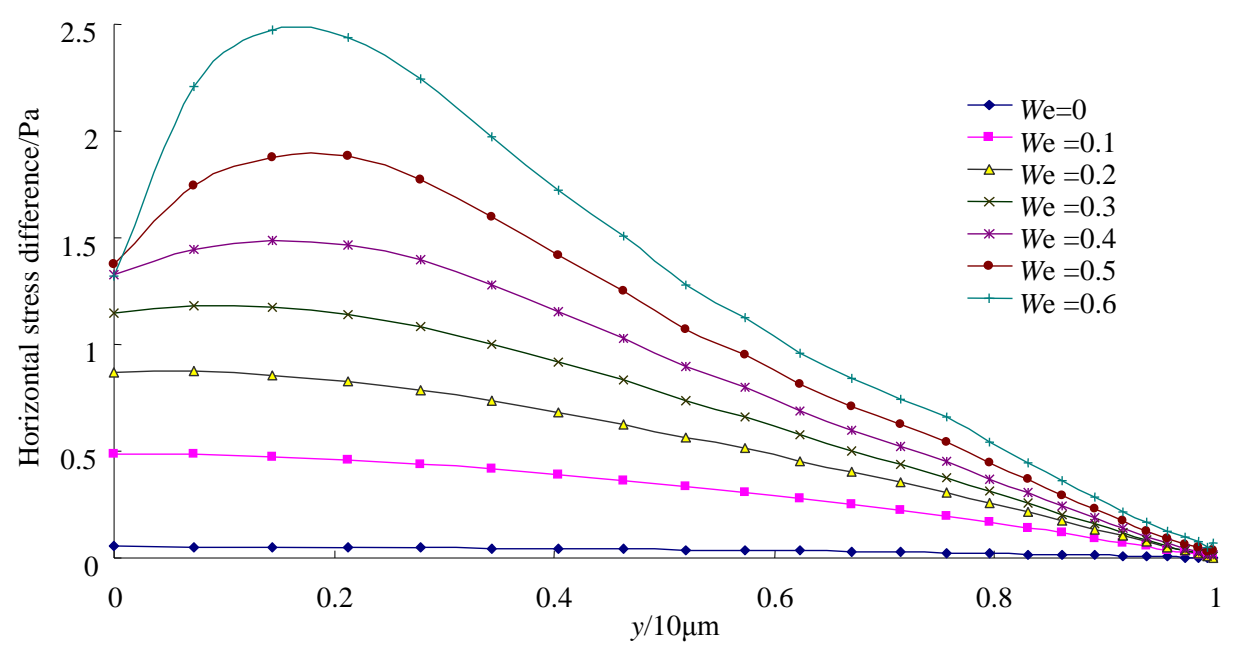

(a)

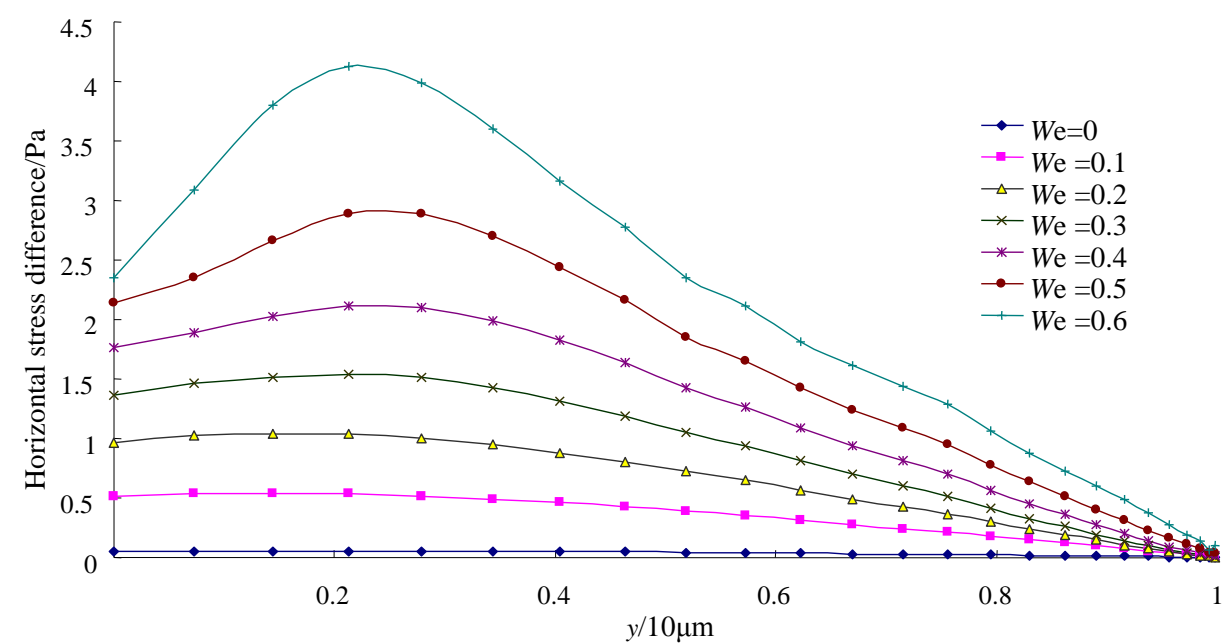

(b)

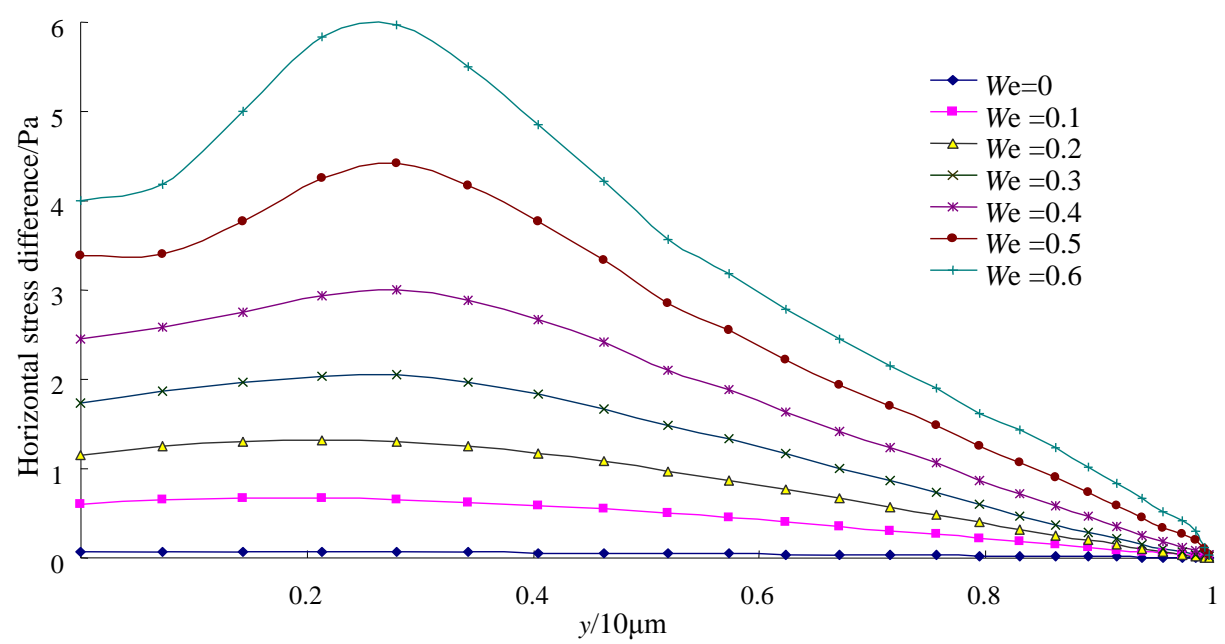

(c)

Figure 2. The horizontal stress difference of residual oil on the surface of oil wet rock. (a) The flow channel width $H=20 \mu \mathrm{m}$; (b) The flow channel width $H=40 \mu \mathrm{m}$; (c) The flow channel width $H=60 \mu \mathrm{m}$. 


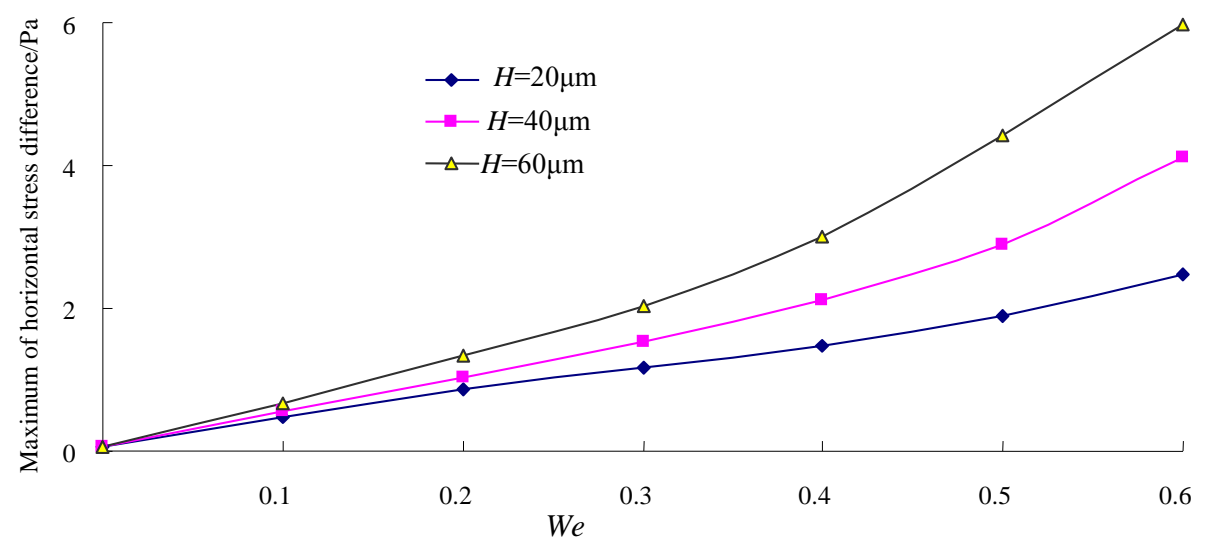

Figure 3. The relationship curve of the maximum of horizontal stress difference and We.

the residual oil will be greater.

2) The greater We (namely, the greater the elasticity of polymer solution) is, the greater the horizontal stress difference acting on the residual oil is.

For class II reservoirs, the concentration of polymer solution can be increased, and the We of the polymer fluid will be increased. Then the force of residual oil can be increased. That is in favor of the deformation of residual oil in low permeability reservoir, which lays the basis for the analysis of residual oil deformation and the separation of the small oil drop from the residual oil.

\section{References}

[1] Yin, H.J., Wang, D.M., Zhong, H.Y., et al. (2012) Flow Characteristics of Viscous-Elastic Polymer. Solution in MicroPores, 1-9.

[2] Yin, H.J., Wang, D.M. and Zhong, H.Y., et al. (2006) Study on Flow Behaviors of Viscous-Elastic Polymer Solution in Micro Pore with Dead End. SPE 101950.

[3] Zhang, L.J., Yue, X.G., Liu, Z.C. and Hou, J.R. (2002) Flow Field of Viscous-Elastic Fluid in Pores with Dead Ends. Journal of Hydrodynamics, Ser A, 17, 748-755.

[4] Wang, D.M., Cheng, J.C., Yang, Q.Y., Gong, W.C., Li, Q. and Chen, F.M. (2000) Viscous-Elastic Polymer Can Increase Displacement Efficiency in Cores. SPE Annual Technical Conference and Exhibition, Dallas, 1-4 October 2000.

[5] Wang, D.M., Wang, G., Wu, W.X., et al. (2008) Influence of the Micro-Force Produced by Viscous-Elastic Displacement Liquid on Displacement Efficiency. Journal of Xi'an Shiyou University (Natural Science Edition), 23, 43-55.

[6] Xia, H.F., Ye, J. and Kong, F.S. (2004) Effect of Elastic Behavior of HPAM Solutions on Displacement Efficiency on Mixed Wettability Conditions. SPE Asia Pacific Oil and Gas Conference and Exhibition, Perth, 18-20 October 2004.

[7] Xia, H.F., Wang, D.M., Wang, G., et al. (2009) Effect of Micro Forces Caused by Driving Fluid with Viscous-Elasticity on Residual Oil in Chemical Flooding. Journal of China University of Petroleum (Natural Science Edition), 33, 151-155.

[8] Han, S.F. (2000) Non-Newtonian Fluid Constitutive Equation and Calculative Analytic Theory. Science Press, Beijing, 102. 